\title{
Growing Farther Apart: Racial and Ethnic Inequality in Household Wealth Across the Distribution
}

\section{Michelle Maroto}

University of Alberta

\begin{abstract}
This article investigates net worth disparities by race and ethnicity using pooled data from the 1998-2013 waves of the U.S. Survey of Consumer Finances. I apply unconditional quantile regression models to examine net worth throughout the wealth distribution and decomposition procedures to demonstrate how different factors related to demographics, human capital, financial attitudes, and credit market access contribute to racial wealth disparities. In the aggregate, nonHispanic black households held $\$ 8,000$ less in net worth than non-Hispanic white households at the 10th percentile, $\$ 204,000$ less at the median, and $\$ 1,055,000$ at the 90th percentile. Hispanic households faced similar disadvantages, holding $\$ 4,000$ less in net worth at the 10 th percentile, $\$ 208,000$ less at the median, and $\$ 1,023,000$ less at the 90 th percentile. Disparities continued, but declined, after accounting for labor market disadvantages and credit market access, which again varied across the distribution. Decomposition models show that demographic and income differences mattered more for high-wealth households. These variables accounted for 43-55 percent of the gap for high-wealth households at the 90th percentile but only 10-28 percent at the 10th percentile. Among low-wealth households, differential access to credit markets and homeownership was associated with a larger proportion of the gap in net worth.
\end{abstract}

Keywords: wealth inequality; race and ethnicity; stratification; quantile regression; decomposition

Citation: Maroto, Michelle. 2016. "Growing Farther Apart: Racial and Ethnic Inequality in Household Wealth Across the Distribution." Sociological Science 3: 801-824.

Received: May 11, 2016

Accepted: June 13, 2016

Published: September 12, 2016

Editor(s): Jesper Sørensen, Kim Weeden

D0I: $10.15195 / \mathrm{v} 3 . a 34$

Copyright: (C) 2016 The Author(s). This open-access article has been published under a Creative Commons Attribution License, which allows unrestricted use, distribution and reproduction, in any form, as long as the original author and source have been credited. (C)(i)
$\mathrm{W}$ ITH racial wealth disparities that greatly exceed income gaps, African Americans and Hispanics face continuing disadvantages in housing and credit markets (Conley 1999; Oliver and Shapiro 2006). Due, in part, to high levels of indebtedness, the extension of subprime mortgages, and residential segregation, African American and Hispanic households were especially hard hit during the 2008 recession (Pfeffer, Danziger, and Schoeni, 2013; Wolff 2014). As a result, nonwhite and Hispanic households held only $\$ 18,000$ in net worth at the median in 2013 , far less than the $\$ 142,000$ held by white non-Hispanic households (Bricker et al. 2014; \$2013 USD). Although average racial wealth disparities have been well documented in the literature, less is known about how these disparities vary among low- and high-wealth households. Even middle and upper class racial minority households still must deal with racism and discrimination (Bonilla-Silva 2013), and it is likely that such factors spill over into areas of wealth.

In light of these issues, this article investigates wealth disparities by race and ethnicity in the United States and focuses on the following research questions: how do wealth disparities experienced by non-Hispanic black and Hispanic households vary across the wealth distribution? And, do the same factors contribute equally to racial wealth inequality among low- and high-wealth households? Racial wealth disparities are associated with multiple characteristics that include demographics and family structure, income and education, financial attitudes, and credit market 
access, as well as minorities' experiences of segregation and discrimination (Campbell and Kaufman 2006; Keister 2004; Oliver and Shapiro 2006). Although research has demonstrated how these factors matter for racial inequality at the center of the distribution, their relative importance might vary for low- and high-wealth households.

This article uses data from six waves of the Survey of Consumer Finances (SCF, 1998-2013) to examine disparities across two racial minority groups in the distribution of net worth in the United States. I first employ unconditional quantile regression models to show how net worth disparities increase throughout the wealth distribution. I then use decomposition procedures to determine how various factors related to demographics, human capital, financial attitudes, and credit market access contribute to these wealth disparities.

My results show that racial wealth inequality varies across the distribution, where low- and high-wealth black and Hispanic households do not face the same disadvantages. In the aggregate, non-Hispanic black households held $\$ 8,000$ less in net worth than non-Hispanic white households at the 10th percentile, $\$ 204,000$ less at the median, and $\$ 1,055,000$ less at the 90 th percentile. After accounting for key covariates, these disparities decreased to $\$ 2,000$ at the 10th percentile, $\$ 61,000$ at the median, and $\$ 194,000$ at the 90th percentile for non-Hispanic black households. Hispanic households held $\$ 4,000$ less in net worth at the 10th percentile, $\$ 208,000$ less at the median, and $\$ 1,023,000$ less at the 90th percentile when not accounting for other factors. Once control variables, particularly those related to credit market access, were included, Hispanic households actually held \$2,800 more in net worth than otherwise similar non-Hispanic white households at the 10th percentile and $\$ 45,000$ less at the median, with few significant differences at the highest percentiles. In addition to these descriptive results, decomposition models emphasize how predictors of wealth function in different ways across the broader distribution, further demonstrating a need to move beyond average differences when studying wealth inequality.

\section{Racial Wealth Inequality}

Strengthened by differential returns to resources that largely benefit white households in the United States, wealth gaps by race and ethnicity have been increasing since the 2008 recession (Pfeffer et al. 2013; Wolff 2014). Black households are less likely to own their homes, have lower levels of net worth, and accumulate fewer assets than white households over time (Gittleman and Wolff 2004; Killewald 2013; Kuebler and Rugh 2013). Additional research has also shown significant disparities in wealth accumulation, homeownership rates, and home equity between white and Hispanic households (Campbell and Kaufman 2006; Flippen 2004; Krivo and Kaufman 2004). Even after accounting for variation in education and income, large racial wealth gaps remain (Oliver and Shapiro 2006).

Although average racial wealth disparities have been well documented in the literature, we have less information on how racial wealth gaps-and how the components behind these disparities-might vary across the distribution. Because most of the previous studies focus solely on average differences across racial and 
ethnic groups, this only presents a partial picture of racial wealth inequality in the United States. Questions remain as to whether wealth disparities by race still exist at the high and low ends of the wealth distribution, and, perhaps more importantly, whether the same components contribute equally to racial wealth inequality among low- and high-wealth households.

\section{Interconnected Components of Wealth Inequality}

Although household wealth accumulates through the primary processes of labor market income and inheritance, multiple individual and structural factors contribute to racial wealth disparities (Spilerman 2000). These include family structure and demographic differences as discussed in microeconomic models, disadvantages in other areas that include employment and education, variation in financial behavior and attitudes, and differential access to inheritance, family assistance, and credit markets as a whole. Each set of explanations connects with the others, and, as part of a broader system of cumulative disadvantage, many of these explanations overlap to compound inequality across groups (DiPrete and Eirich 2006). Importantly, these factors can also be connected to the broader and more structural forces of historical and contemporary discrimination across markets (Reskin 2012).

\section{Demographics and Family Structure}

Basic demographic differences related to age, marital status, and family formation largely influence wealth disparities for groups. As indicated by life-cycle hypotheses, age and net worth are highly connected, as wealth increases for most individuals through their sixties and then begins to decline with retirement (Spilerman 2000). Along with age, family structure and certain life course events, such as marriage and parenthood, are also associated with changes in wealth (Addo and Lichter 2013; Vespa and Painter 2011). Rates of single parent households are much higher among black and Hispanic families, and members of these groups more often live in multigenerational households, which can also strain household resources and limit wealth (Cohen and Casper 2002). As a result, aggregate racial differences in wealth partly stem from differences in family composition and formation that occur over the life course (Addo and Lichter 2013; Keister 2004).

\section{Education, Employment, and Income}

Disadvantages in education, employment, and income can also influence wealth (Bricker et al. 2014). Households with higher education levels and greater income enjoy better access to credit markets and increased asset accumulation, which disadvantages racial minorities with less education and income (Bricker et al. 2014; Scholz and Sheshardi 2009). Family poverty, a consequence of labor market inequality, also impedes minorities' transitions into homeownership and overall wealth levels (Chiteji and Hamilton 2002; Heflin and Pattillo 2006). Thus, racial disparities in education, employment, and income are likely connected to disparities in credit markets and wealth. 


\section{Financial Attitudes and Savings Behavior}

Standard microeconomic models point toward differences in financial literacy, monetary attitudes, and savings behavior as potential explanations for wealth disparities. Studies in this area stress habit formation and behavior, concepts that have been incorporated into savings programs such as Individual Development Accounts, as a means for households to increase savings and overall wealth (Loibl, Kraybill, and DeMay 2011). They also emphasize planning for retirement and knowledge of financial products as key components of economic wellbeing (Fernandes, Lynch, and Netemeyer 2014). Financial literacy differs with age, education, and gender, and studies show that it can influence retirement savings and certain consumer choices, such as those related to willingness to invest in stocks (Lusardi and Mitchell 2007; Van Rooij, Lusardi, and Alessie 2011). However, results vary with the study methodology. Financial education interventions tend to have weaker effects than observational studies on financial literacy, which likely occurs because of omitted variable bias (Fernandes et al. 2014).

\section{Credit Market Use and Access}

In addition to individual attitudes and savings behavior, credit market access and use are also associated with certain wealth outcomes (Keister 2000a; McCloud and Dwyer 2011). Because homes provide the majority of household assets for most families, racial differences in homeownership largely influence broader disparities in net worth (Kuebler and Rugh 2013). These disparities also extend to home equity, interest rates, and fees (Flippen 2004; Krivo and Kauffman 2004). Beyond homeownership, households headed by racial minorities accumulate less financial wealth and own fewer assets (Chiteji and Hamilton 2002; Scholz and Shesardi 2009), and these disparities increase with the degree of risk (and reward) associated with owning each asset (Keister 2000b). Racial minorities also have less attachment to traditional or mainstream financial institutions, which often results in an overreliance on costly subprime lenders (Caskey 1996). Members of these groups are more likely to be "unbanked," lacking checking or savings accounts, and are often discouraged from borrowing (Scholz and Sheshardi 2009).

Differences in the incidence and amount of intergenerational transfers further work to maintain racial wealth gaps, even after accounting for income disparities. Because of large differences in parental wealth and family size, white households pass on larger sums to their children, producing a racial advantage across generations (Conley 1999, 2001; Oliver and Shapiro 2006; Spilerman 2000). Siblings and extended family can also strain family finances early on, which leaves parents with less to pass on to their children (Keister 2003, 2004). Consequently, the receipt of large gifts or inheritances constitutes approximately 10 to 20 percent of the racial wealth disparities across households (Avery and Rendall 2002; Gittleman and Wolff 2004; McKernan et al. 2014). 


\section{Broader Forces}

Despite so many relevant predictors of wealth, average racial gaps remain even after accounting for employment, education, and parental wealth (Conley 2001; Keister 2000b). This likely occurs because racial inequality across these areas still stems from broader causes connected to both historical and contemporary discrimination. Policies instituted within racial regimes many years ago still have lingering effects on present day groups (Oliver and Shapiro 2006; Shapiro 2004), and studies demonstrate that minority groups continue to face discrimination in employment, housing, and other areas (Pager and Shepherd 2008) as well as residential segregation (Massey and Denton 1993). Thus, factors that I cannot control for, such as discrimination and residential segregation, should also connect to inequalities within credit markets to further limit wealth accumulation for racialized groups.

\section{Relationships Across the Distribution}

Taken together with broader forces, these four sets of factors related to (1) basic demographics and family structure; (2) income, education, and employment; (3) financial attitudes and behaviors; and (4) credit market access help to account for a large proportion of the racial inequality in wealth in the United States, at least at the center of the distribution. They demonstrate how inequality connects to age, family structure, portfolio behavior, employment, education, and inheritance for the average household. However, questions remain as to whether these factors influence wealth outcomes in a similar manner at all points of the distribution. For example, do they matter equally for high- and low-wealth non-Hispanic black and Hispanic households? Because factors such as demographics, employment, and credit market access might shape inequality among high- and low-wealth households in different ways, this requires an analysis across the wealth distribution, which I accomplish by decomposing the racial wealth gap explained by each set of variables for high- and low-wealth households.

\section{Data}

I study the relationship between race and wealth accumulation using data from the 1998, 2001, 2004, 2007, 2010, and 2013 surveys of the U.S. Survey of Consumer Finances (SCF). The SCF is a triennial, cross-sectional survey of U.S. households, conducted by the Economic Research and Data branch of the U.S. Federal Reserve. This survey uses the household, or the "primary economic unit" (PEU), as the unit of analysis. The PEU refers to the "economically dominant, financially interdependent family members within the sampled household" (Board of Governors 2014). For each survey wave, the primary respondent in a given household is the economically dominant single individual or the financially most knowledgeable member of the economically dominant couple. However, the survey also collects demographic and employment information for other family members. 
The SCF includes detailed financial information for households related to income, asset ownership, and debt. Although multiple cross-sectional and longitudinal U.S. surveys (e.g., the National Longitudinal Survey of Youth and the Panel Study of Income Dynamics) now include information on wealth, the SCF provides the most detailed assets and debt data available. The survey also employs strategic sampling to include high-wealth and high-income households, who are often missed in less-targeted surveys. Incorporating these households is necessary for understanding wealth disparities across the distribution.

I analyze five imputed samples of 6,015 households from the 2013 SCF, 6,482 households from the 2010 data, 4,417 households from the 2007 data, 4,519 households from the 2004 data, 4,442 households from the 2001 data, and 4,305 households from the 1998 data for a total pooled sample of 30,180 households. ${ }^{1}$ Thus, my data span 15 years and cover periods before, during, and after the 2008 recession. In order to account for sampling strategies and complex data, I incorporate sampling weights in all analyses, and I apply Rubin's (1996) techniques to combine multiple imputation samples.

\section{Measures}

My key outcome variable is total net worth, measured as total assets net liabilities. Total assets include property, vehicles, businesses, pensions measured on an ongoing basis, and other types of financial and nonfinancial assets. Total debt or liabilities include outstanding balances on credit cards, mortgages, lines of credit, vehicle debt, education debt, traditional consumer credit, and other types of loans (Kennickell and Woodburn 1992). All monetary values are adjusted for inflation and appear in 2013 U.S. dollars.

As my primary predictor variables, I include two variables that indicate whether the respondent identified as black or Hispanic, making the referent category nonHispanic white. ${ }^{2}$ I also control for the final racial category included in the SCF of "other." This includes respondents who identified as Asian, American Indian, Alaska Native, Native Hawaiian, Pacific Islander, or other. As shown in Table 1, which provides weighted descriptive statistics for my key variables broken down by race and ethnicity, 13 percent of respondents identified as non-Hispanic black and nine percent identified as Hispanic in the survey.

To account for different components of wealth inequality, I incorporate four sets of covariates related to (1) basic demographics and family structure; (2) income, education, and employment; (3) financial attitudes and behaviors; and (4) credit market access and use in my models. Demographic variables address the respondent's age, disability status, household composition, and gender. I include age along with a quadratic term to address any nonlinearity in the relationship. I also control for whether the respondent or the respondent's spouse reported a disability. To account for household structure and gender, I include a household type variable of two adult partners (the referent), single male adult, and single female adult as well as variables that measure household size and whether any children under age 18 were present in the household. ${ }^{3}$ Together, these variables provide a description of 


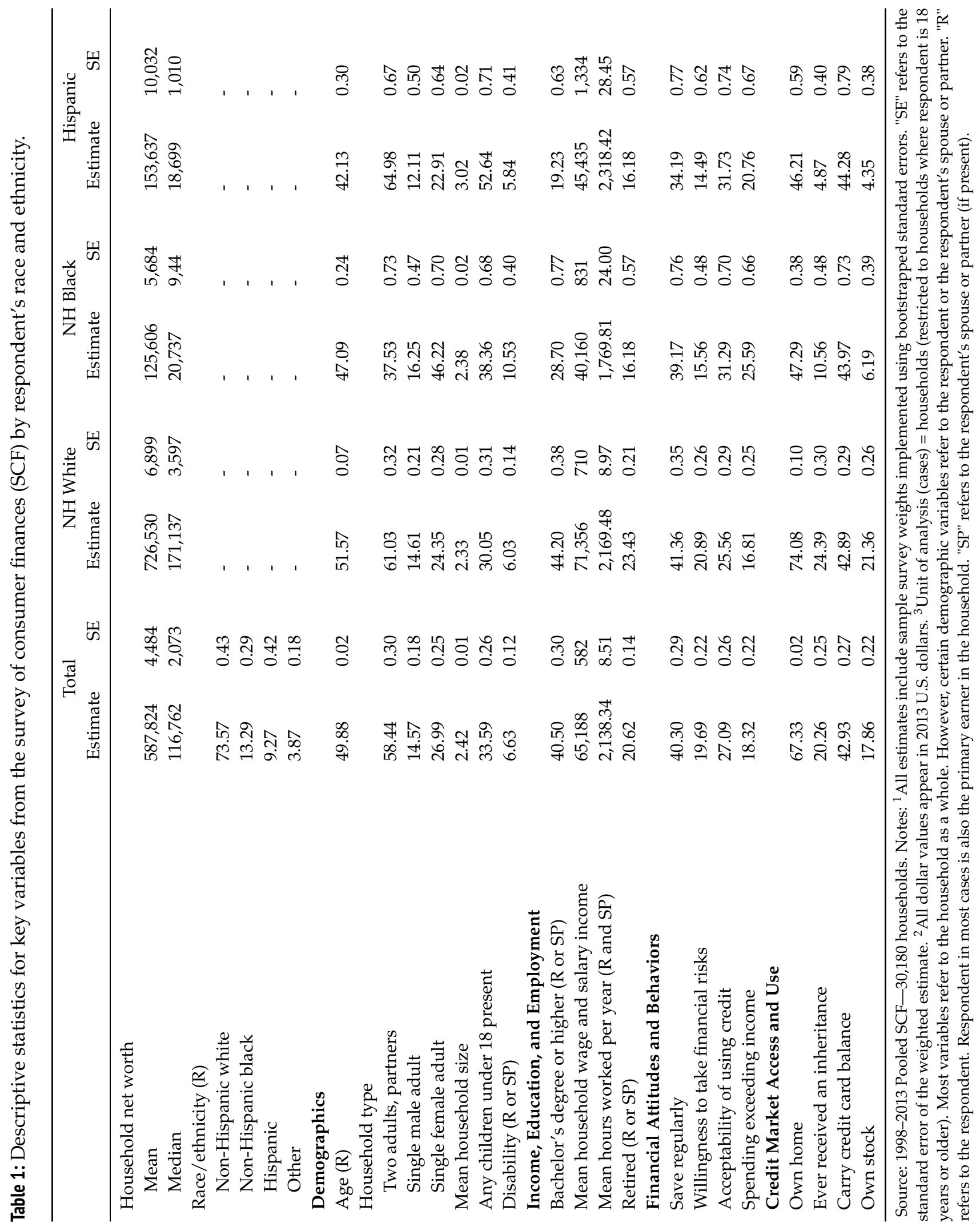


household structure that accounts for family size, respondent sex, and the presence of children.

As measures of household education and labor market situation, I control for whether the respondent or the respondent's spouse attained a bachelor's degree or higher, the total household wage and salary income, whether the respondent or spouse was retired, and the total hours worked per year within the household. Approximately 41 percent of households had at least one person with a bachelor's degree present, and, across households, the mean household wage and salary income was $\$ 65,000$. Black and Hispanic households earned less in income and were also less likely to have a person with a bachelor's degree present.

As measures of financial behavior, I include variables indicating whether the household saves regularly by putting aside money on (at least) a monthly basis and whether the household's spending exceeded income over the past year. ${ }^{4}$ As shown in Table 1, 40 percent of households regularly saved and 18 percent had expenses that exceeded their income in the past year. I also include a measure describing the household's willingness to take financial risks. This variable indicates whether the respondent or spouse would take above average or substantial risks on investments. Finally, I include a variable that indicates whether the respondent or spouse thought it was a good idea to borrow with credit. Nineteen percent of households were willing to take financial risks and 27 percent thought that it was acceptable to borrow with credit.

In order to control for credit market access and use, I incorporate four categorical variables that indicate whether the respondent or the respondent's spouse owned a home, received an inheritance, carried a credit card balance, or owned any stocks. Inheritances, home ownership, and stock investments generally increase net worth, while carrying credit balances tends to have a negative association with net worth (Conley 2001; Spilerman 2000). Approximately 67 percent of households owned their homes, 18 percent owned stock, 20 percent received an inheritance, and 43 percent carried credit card balances (Table 1).

\section{Methods}

For the first part of my analysis, I use unconditional quantile regression (UQR) models to estimate the association between certain covariates at different levels of a household's total net worth. Unlike conditional quantile regression (CQR) models, in which control variables essentially redefine each quantile, UQR models define quantiles in relation to the unconditional wealth distribution (Firpo, Fortin, and Lemieux 2009). This allows me to ascertain how the association between race and net worth varies across the wealth distribution. I follow Firpo et al. (2009) and estimate UQR models using the recentered influence function (RIF) and ordinary least squares (OLS) regression. ${ }^{5}$ Equation (1) defines the RIF, which I calculate for each quantile of interest:

$$
\operatorname{RIF}\left(Y ; q_{\tau}\right)=q_{\tau}+\left(\tau-I\left\{Y \leq q_{\text {tau }}\right\}\right) / f_{y}\left(q_{\tau}\right)
$$


where $\tau$ is the given quantile, which, in this case, is a range of values from 0.05 through $0.95 ; q_{\tau}$ is the value of the outcome variable, net worth, $Y$, at the $\tau$ th quantile; $f_{y}\left(q_{\tau}\right)$ is the density of $Y$ at $q_{\tau}$; and $I$ is an indicator function.

I then use a basic regression framework where I replace the outcome, $Y$, with $\operatorname{RIF}\left(Y ; q_{\tau}\right)$ for each quantile to estimate unconditional partial effects across quantiles. I incorporate survey replicate weights and bootstrap standard errors for all analyses. I also rely on Rubin's methods to combine results from the five imputed SCF samples (Rubin and Schenker 1986; Rubin 1996). I therefore average coefficients across imputed samples and account for variation within and between samples in my standard errors.

In the second part of my analysis, I decompose the racial wealth gap into its explained and unexplained components using a Blinder-Oaxaca decomposition model at different parts of the distribution (Blinder 1973; Oaxaca 1973). The explained components of the model refer to the difference in group outcomes that are associated with model covariates (i.e., differences in characteristics across groups). The unexplained portion of the analysis reflects unmeasured compositional variables (i.e., differences in coefficients). I use coefficients from a two-fold decomposition model that is pooled over both samples with a group membership indicator, and I discuss how specific covariates explain the wealth gap at different parts of the distribution.

\section{Findings}

My results show that racial and ethnic wealth disparities vary across groups and increase throughout the wealth distribution in the United States. Demographic, labor, and credit market access variables accounted for much of the racial wealth gap, but the relative importance of these factors varied across low- and highwealth households. In addition, non-Hispanic black and Hispanic households both experienced wealth disparities after incorporating these key predictor variables.

\section{Racial Inequality in Net Worth}

To begin with a general description of racial wealth inequality, Figure 1 highlights large and continuing disparities in mean and median net worth by race and ethnicity that persist over time. At the mean in 2013, non-Hispanic white households held seven times as much in net worth as non-Hispanic black households and six times as much as Hispanic households. The gap was actually larger at the median, where non-Hispanic households held 12 times the wealth of non-Hispanic black households and 10 times the wealth of Hispanic households. These gaps have also fluctuated with broader changes in the economy. For instance, non-Hispanic white households experienced larger absolute declines in mean and median net worth after the 2008 recession, but non-Hispanic black and Hispanic households experienced larger relative declines. 


\section{A: Mean Net Worth}

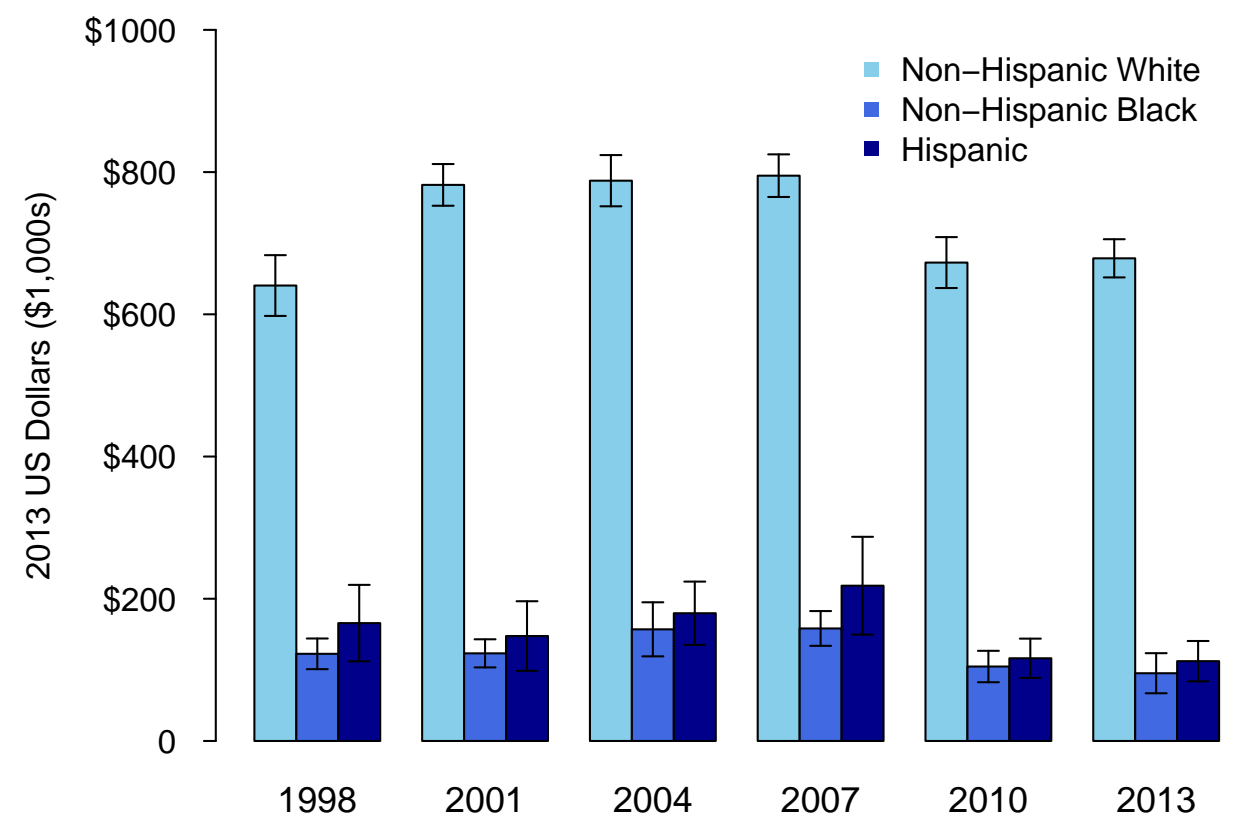

\section{B: Median Net Worth}

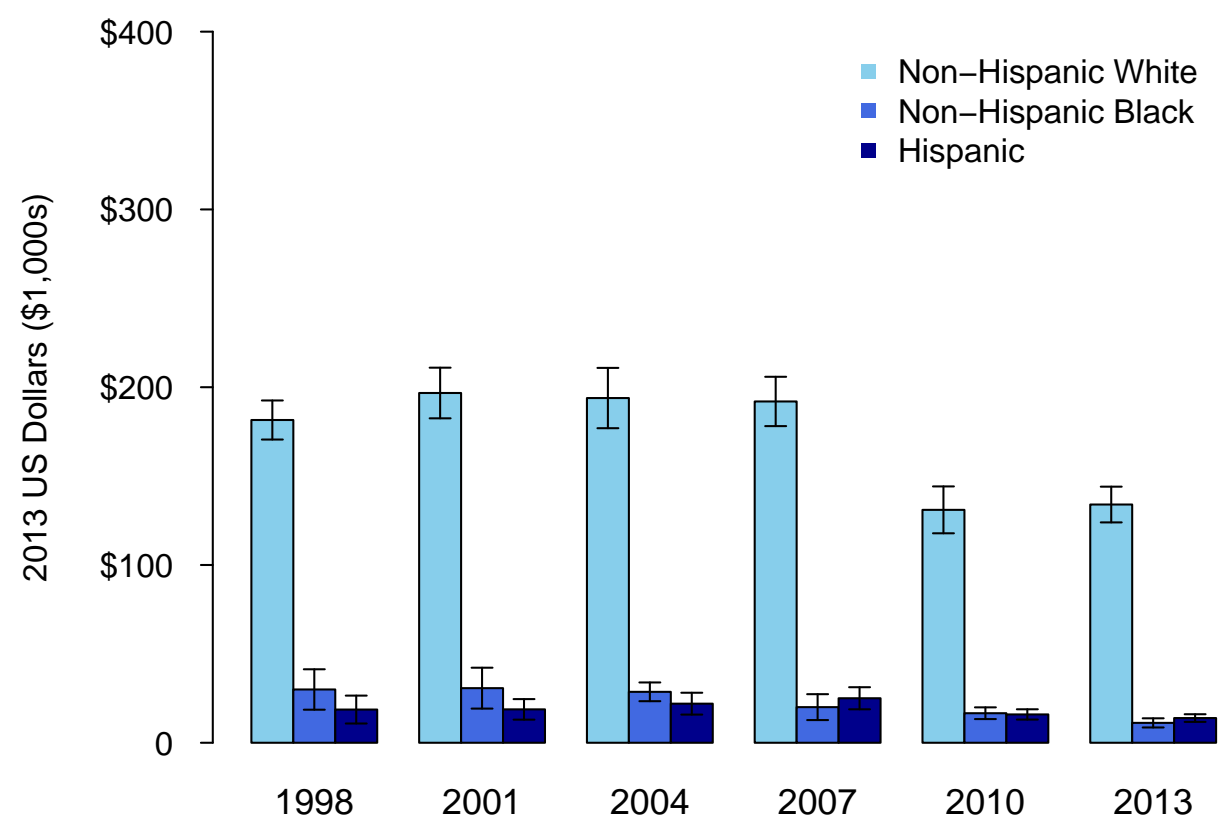

Figure 1: Mean and median net worth by race and ethnicity, 1998-2013.

Notes: Figure 1 presents mean and median net worth levels for non-Hispanic white, non-Hispanic black, and Hispanic households in thousands of 2013 U.S. dollars for the 1998-2013 waves of the SCF. The figure includes estimates and 95 percent confidence intervals. 


\section{A: Non-Hispanic Black Households}

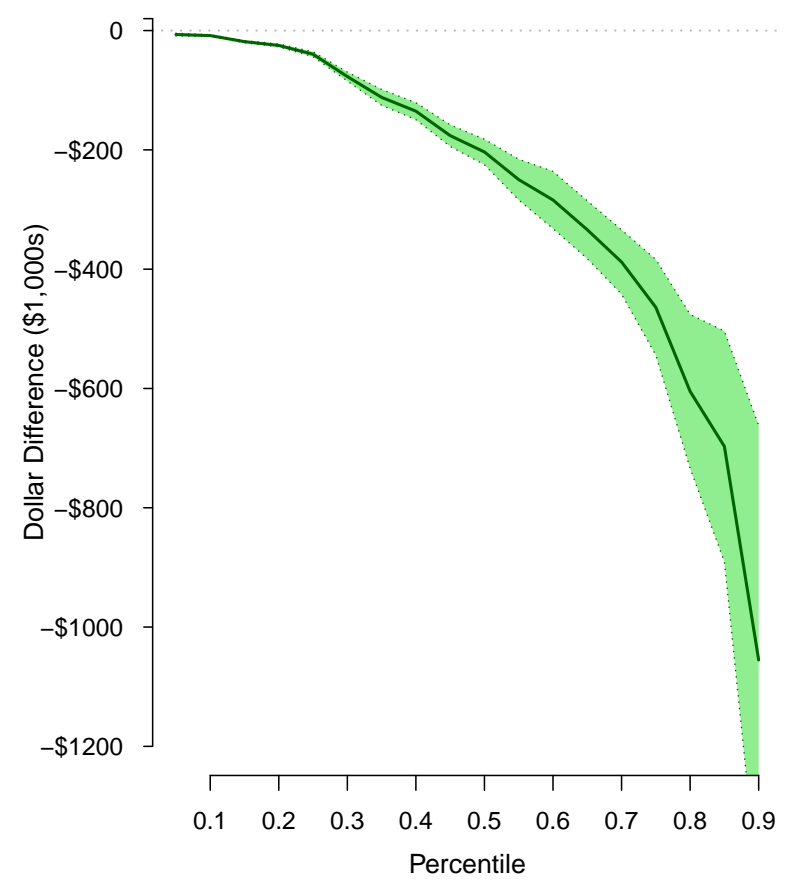

\section{B: Hispanic Households}

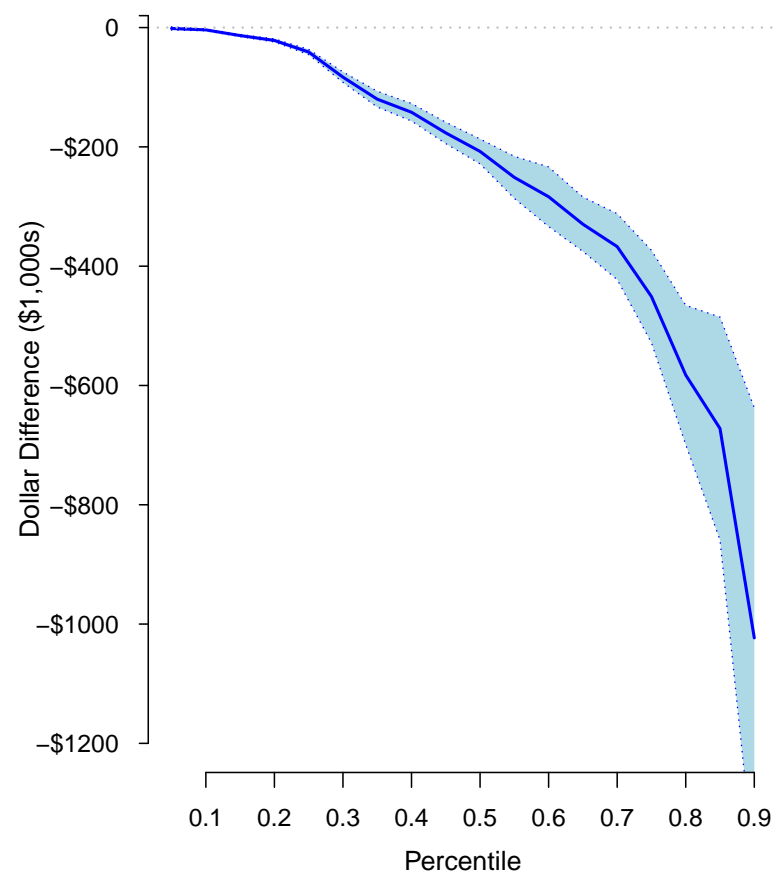

Figure 2: Difference in net worth by race, ethnicity, and percentile, 1998-2013, no controls.

Notes: Figure 2 presents the unconditional difference in net worth across the distribution for non-Hispanic black households (Panel A) and Hispanic households (Panel B) when compared to non-Hispanic white households in 2013 U.S dollars. The figure includes estimates and 95 percent confidence intervals. Models also account for year.

\section{Inequality in Net Worth Across the Distribution}

Although Figure 1 presents continuing disparities at the center of the wealth distribution, it is also important to study disparities at different levels of net worth. To illustrate variation across the distribution, Figure 2 plots net worth disparities for non-Hispanic black and Hispanic households in comparison to non-Hispanic white households at each percentile of net worth. As shown in both panels of the figure, racial and ethnic net worth disparities, as measured in dollar amounts, increase almost exponentially as household wealth levels increase. However, although dollar disparities grow throughout the distribution, proportionately the increase is less dramatic.

At the 75th percentile, the gap between non-Hispanic white and non-Hispanic black households was approximately $\$ 464,000$, and the gap for Hispanic households was $\$ 451,000$. These disparities more than doubled to $\$ 1,055,000$ and $\$ 1,023,000$ at the 90th percentile. Despite the large disparities among high-wealth households, negligible differences appeared among low-wealth households of about $\$ 4,000$ to $\$ 8,000$ at the 10 th percentile. Thus, this figure presents large racial wealth disparities that grow throughout the wealth distribution. However, it does not 


\section{A: Non-Hispanic Black Households}

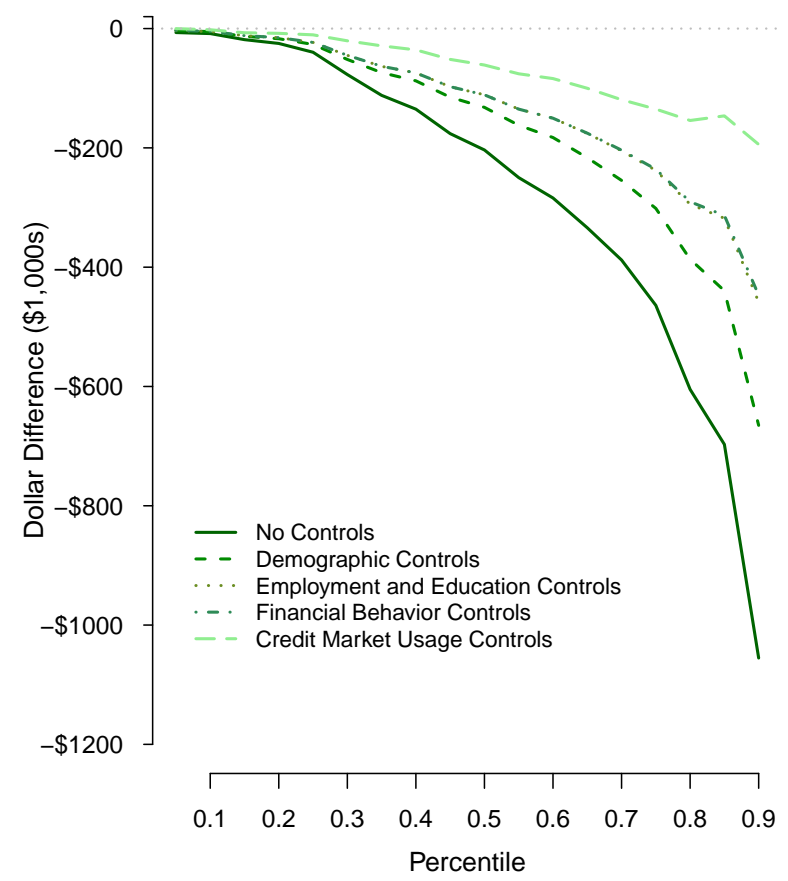

\section{B: Hispanic Households}

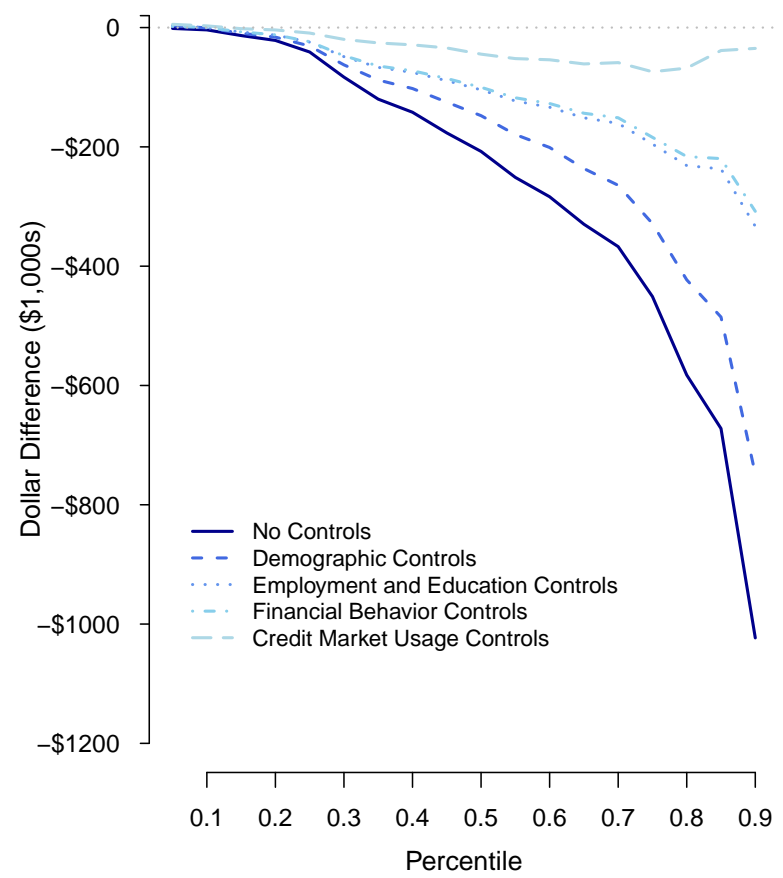

Figure 3: Difference in net worth by race, ethnicity, and percentile, 1998-2013, controls.

Notes: Figure 3 presents the unconditional difference in net worth across the distribution for non-Hispanic black households (Panel A) and Hispanic households (Panel B) when compared to non-Hispanic white households in 2013 U.S dollars, conditional on four sets of covariates.

include potential explanations for such disparities, which requires a more in-depth investigation across low- and high-wealth households.

Figure 3 plots the same racial wealth distribution for non-Hispanic black and Hispanic households present in Figure 2, but this figure now includes four sets of covariates in order to depict their relationship with net worth. ${ }^{6}$ This figure presents results from unconditional quantile regression models that sequentially added (1) demographic, (2) income, education, and employment, (3) financial attitudes and behaviors, and (4) credit market access predictors to demonstrate how the addition of control variables influenced net worth across race and ethnic groups. Together, these covariates account for a large percentage of the racial wealth gap. However, the gap was still larger at higher ends of the distribution, disparities remained in models that included all controls, and these disparities were larger for non-Hispanic black households.

After accounting for all controls, non-Hispanic black households held about $\$ 2,000$ less in net worth than otherwise similar non-Hispanic white households in the United States at the 10th percentile. The disparity increased to $\$ 11,000$ at the 25 th percentile, $\$ 61,000$ at the median, $\$ 135,000$ at the 75 th percentile, and $\$ 194,000$ at the 
90th percentile. Hispanic households faced a similar pattern, but wealth disparities for this group were much smaller. Hispanic households actually held about $\$ 2,800$ more in net worth than otherwise similar non-Hispanic white households at the 10th percentile. However, for wealthier households, the sign reversed-they held $\$ 9,000$ less at the 25 th percentile, $\$ 45,000$ less at the median, and $\$ 75,000$ less at the 75 th percentile. At the 90 th percentile, no significant wealth differences emerged between non-Hispanic white and Hispanic households after accounting for other factors.

The additional covariates show that net worth was also associated with most controls, but these relationships varied across the wealth distribution yet again. Certain variables, such as age, income, education, and homeownership, were consistently associated with wealth outcomes at all levels. However, the importance of other variables, such as financial attitudes and behaviors, varied considerably with the level of wealth. In order to better understand the relationship among these factors and racial wealth inequality, I apply a series of decomposition models in the following section.

\section{Decomposition Models}

Tables 2 and 3 present results from models that decomposed gaps in net worth across race and ethnic groups at the 10th, 25th, 50th, 75th, and 90th percentiles of the wealth distribution. Decomposing racial wealth disparities into their explained and unexplained components in these tables helps to illustrate which factors are more strongly associated with racial wealth gaps at different points in the distribution. Table 2 refers to the gap between non-Hispanic black and non-Hispanic white households, and Table 3 refers to the gap between Hispanic and non-Hispanic white households. ${ }^{7}$ Figure 4 then combines these results to plot the percentage of the explained net worth gap attributable to different factors for non-Hispanic black households in Panel A and Hispanic households in Panel B.

Sets of covariates influenced less of the inequality in wealth experienced by non-Hispanic black households in Table 2 than they did for Hispanic households in Table 3. However, among both groups, covariates explained more of the wealth disparity at the high and low ends of the distribution and less at the middle of the distribution. For instance, these factors accounted for 75 percent of the gap at the 10th percentile and 85 percent at the 90th percentile but only 62 percent at the median for non-Hispanic black households. The difference was less apparent among Hispanic households; covariates accounted for 83 percent of the gap at the 10th percentile, 91 percent at the 90th percentile, and 82 percent at the median.

The relative strength of these covariates also varied across the distribution for both groups, and the pattern differed across non-Hispanic black and Hispanic households, as shown in Figure 4. For non-Hispanic black households, demographics, income, and education accounted for more of the gap at higher wealth levels than at lower levels. For instance, demographics accounted for 13 percent of the disparity among households at the 10th percentile but 25 percent of the disparity among those at the 90th percentile. Among households below the median, employment and income differences explained only 3-8 percent of the gap, but for those 


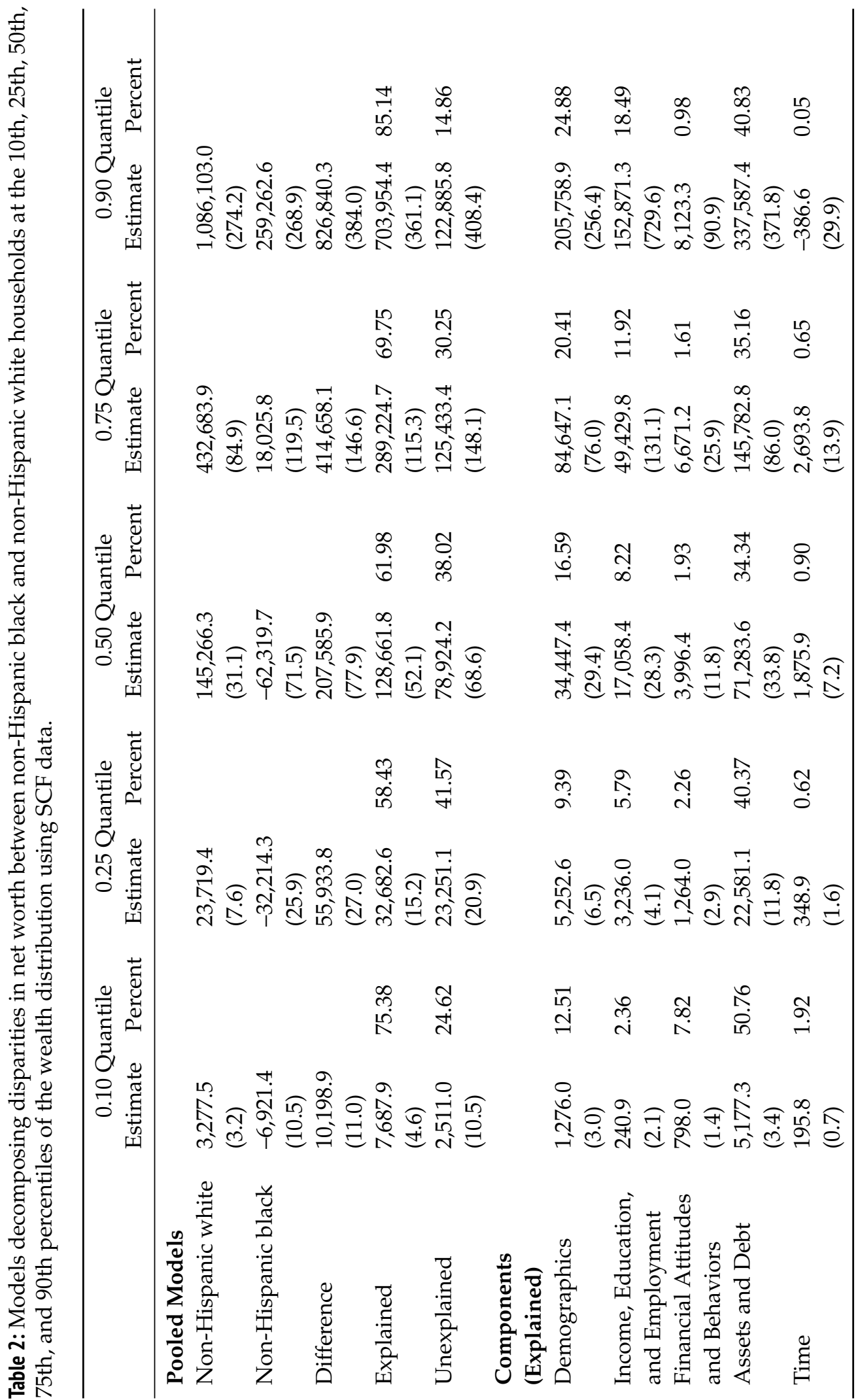




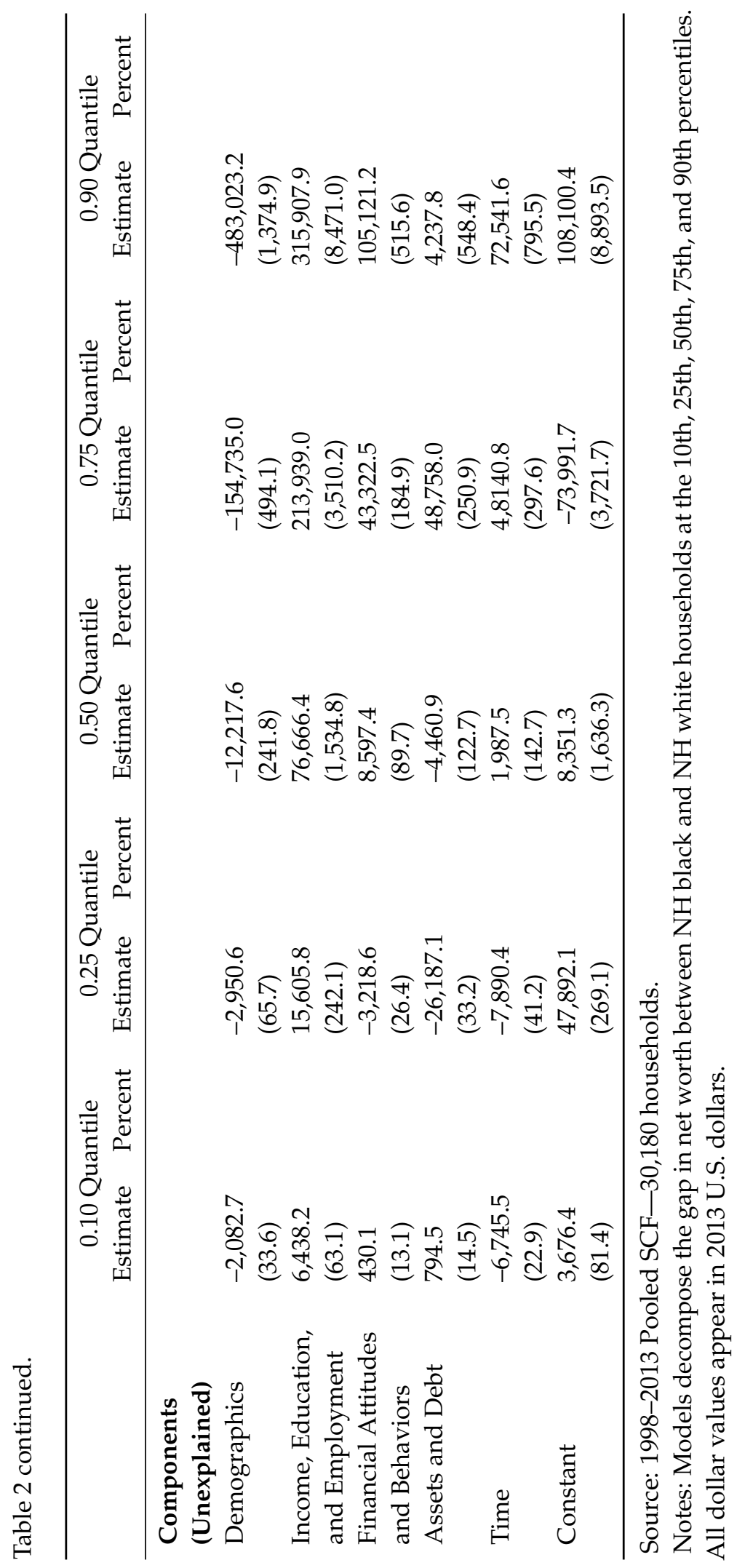




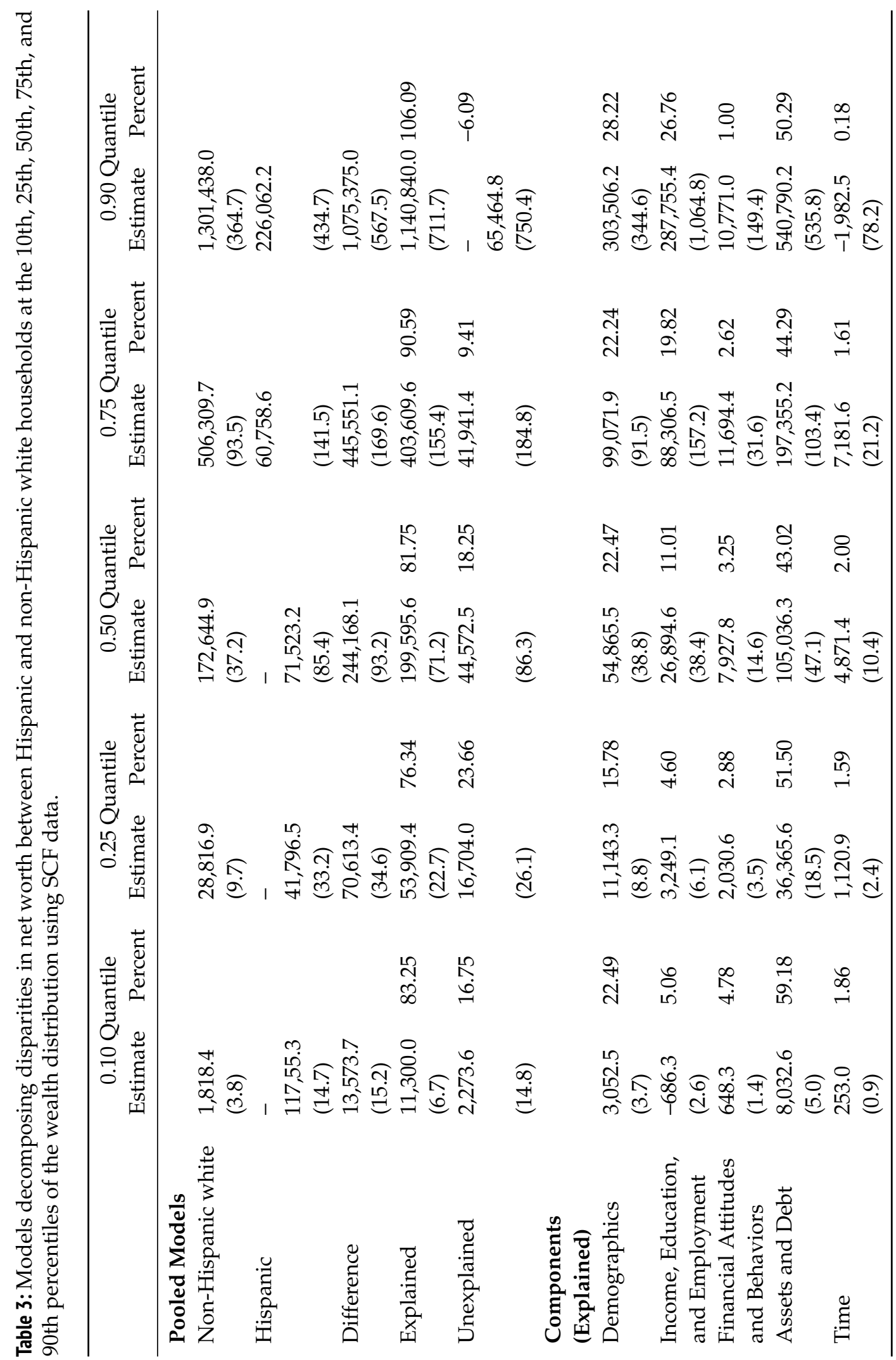




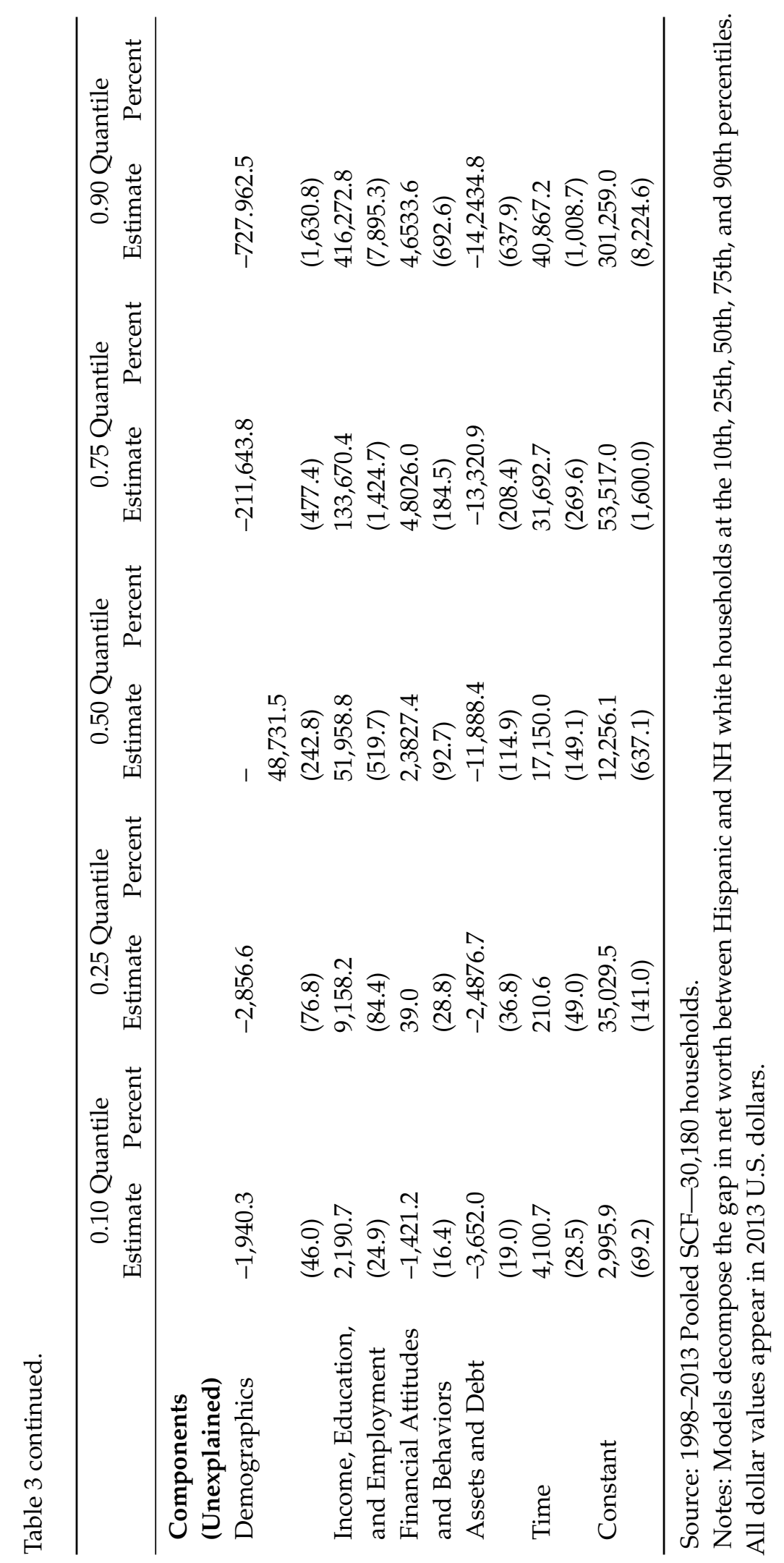




\section{A: Non-Hispanic Black Households}

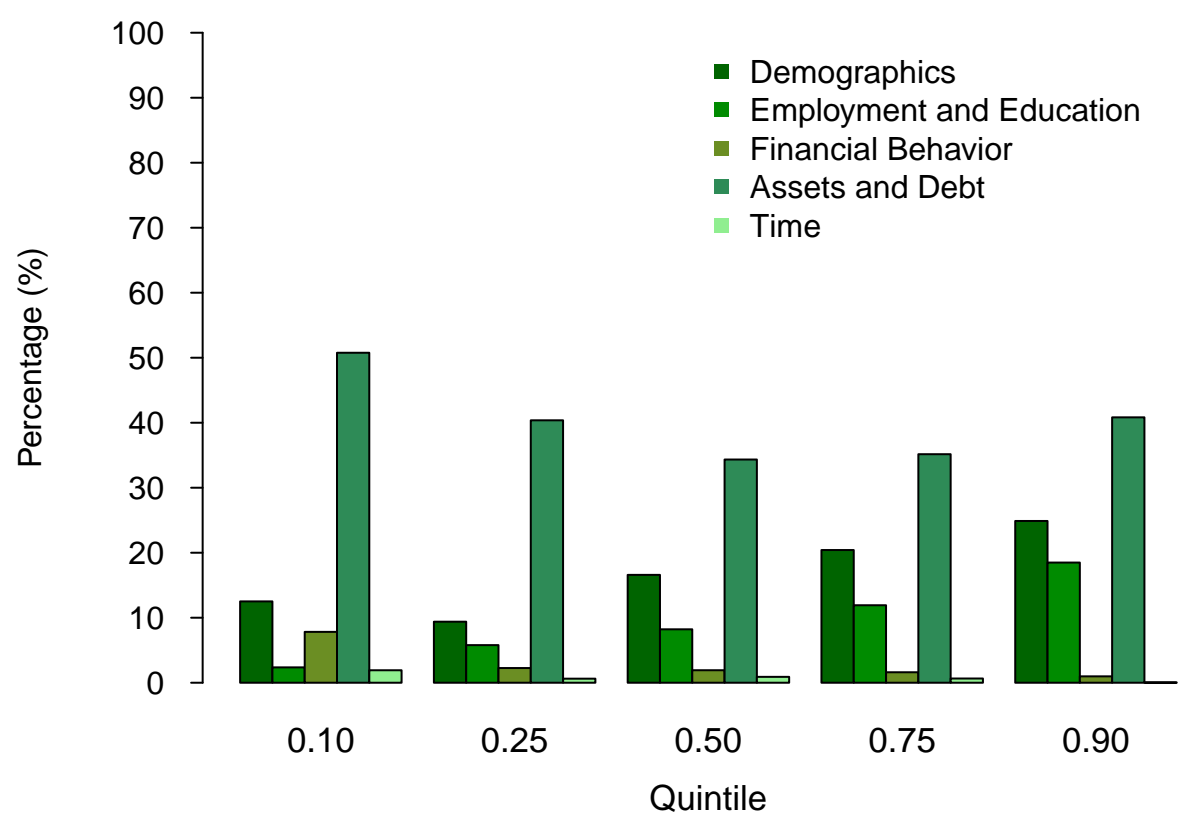

B: Hispanic Households

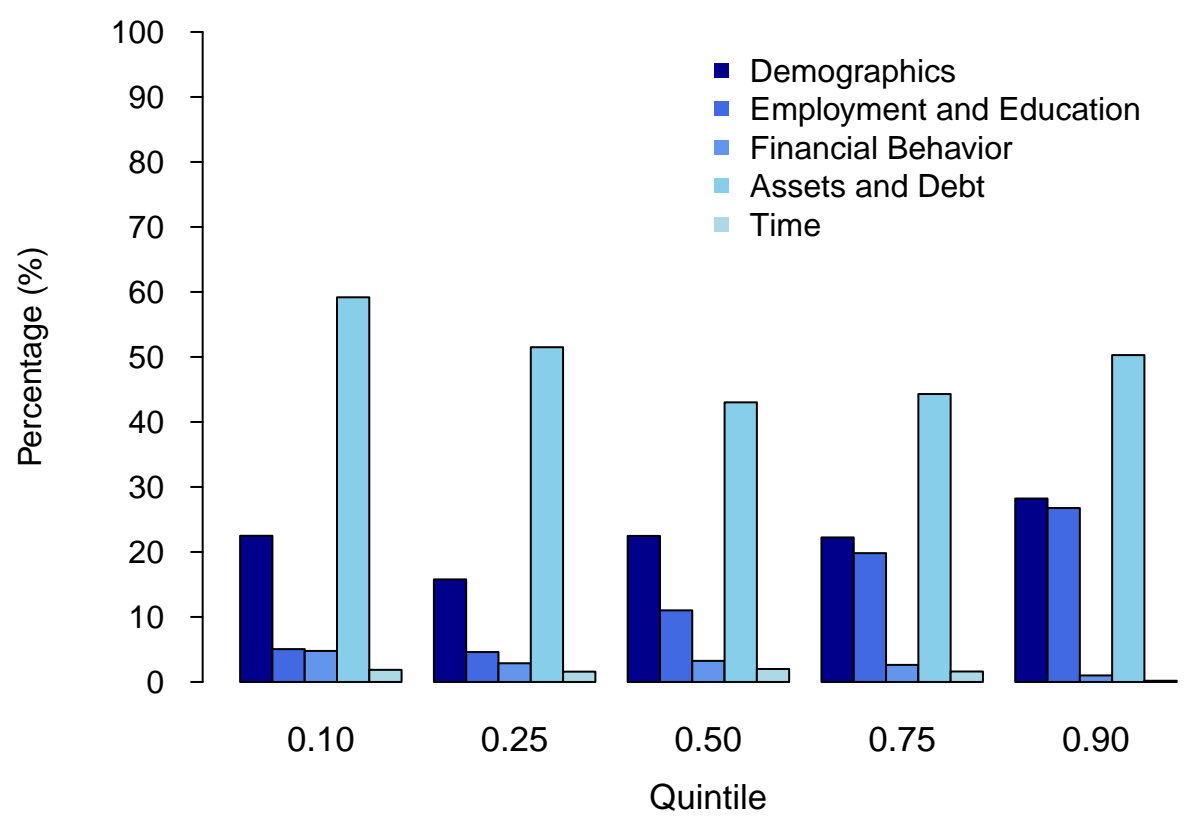

Figure 4: Percentage of explained net worth gap attributable to different factors by quintile, 1998-2013.

Notes: Figure 4 presents results from decomposition models showing the percentages of the explained net worth gap attributable to different factors by quintile for the 1998-2013 waves of the SCF. Estimates come from Tables 2 and 3. 
at the median or above, they constituted 12-18 percent of the gap. The opposite trend held for financial attitudes, saving behaviors, and credit market use variables, which constituted more of the gap at lower wealth levels. Financial behaviors were associated with 8 percent of the gap at the 10th percentile and only 1 percent at the 90th percentile. Finally, as the strongest predictors of wealth inequality, access to assets and debt accounted for 51 percent of wealth inequalities between nonHispanic black and white households at the 10th percentile and 41 percent at the 90th percentile.

In terms of the more detailed predictors (Appendix Table B of the online supplement), education, income, and stock ownership in particular were associated with a larger proportion of the gap at high wealth levels, but homeownership was a much more important factor in explaining gaps for low-wealth households. Differences in homeownership accounted for 43 percent of the black-white wealth gap among low-wealth households, which makes sense because homeownership is the greatest component of wealth for low- to middle-wealth households. At the 90th percentile, however, homeownership explained only six percent of the disparity. Stocks and inheritances were far more important for inequality among the wealthier households, who hold more diverse portfolios and a more likely to receive inheritances overall. Finally, within financial attitudes and behaviors, situations in which spending exceeded income were the main reason why this set of variables was associated with more of the gap at the lower end of the distribution.

Among Hispanic households, covariates accounted for much of the gap across the distribution and almost the entire gap for those at the 75th percentile and above. Demographics explained a similar proportion of the gap (22-29 percent) throughout the distribution for Hispanic households, as shown in Panel B in Figure 4. Similar to non-Hispanic black households, differences in income and education explained more of the gap at higher wealth levels, while financial attitudes and credit market access and use variables were associated with more of the gap at lower wealth levels. For instance, differences in income and education accounted for five percent of the disparity at the 10th percentile but 27 percent at the 90th percentile. Among specific predictors (Appendix Table $\mathrm{C}$ of the online supplement), a bachelor's degree explained seven percent of the disparity at the 10th percentile but 20 percent at the 90th percentile. Differences in assets and debt explained 41-59 percent of the disparity for households below the median and 44-51 percent for those above the median. Again, homeownership was a more important predictor at the low end of the distribution, constituting 60 percent of the gap at the 10th percentile, but inheritance and stocks mattered more at the high end of the distribution.

Decomposing the effects of these explanatory factors on the racial wealth gap illustrates how the relative importance of components of racial wealth inequality varies with the level of wealth. As shown in Figure 3, the relative importance of demographic variables did not change much throughout the distribution, but differences in education and income were more important for disparities among high-wealth families. Even though credit market access and use, factors that some may argue are endogenous to net worth, were the most important factors for racial wealth inequality at all points of the distribution, the relative strength of specific components varied for low- and high-wealth households. Homeownership more 
often distinguished households at the low end of the distribution, but access to stocks and inheritances tended to distinguish high-wealth households.

Despite much research on the relationship between financial behavior and wealth, these predictors were very limited in terms of their relative strength in explaining the racial and ethnic wealth gaps. Views on credit and financial risktaking and even regular savings habits accounted for a very small proportion of the gap in net worth. Experiences in which spending exceeded income tended to be the most important among these predictors. However, although this factor relates to certain aspects of spending behavior, it is also connected to income shocks and circumstances beyond the control of the household. Because low-wealth households are less able to weather such income shocks, this likely influences the effects of this variable on the racial wealth gap among these households.

\section{Discussion}

In this article, I examined net worth disparities for non-Hispanic black and Hispanic households in the United States by combining unconditional quantile regression models and decomposition methods. Instead of solely focusing on a measure of central tendency, UQR models allowed for the investigation wealth disparities throughout the distribution of net worth. Using these models, I found that although multiple factors related to demographics, employment, financial behavior, and credit market usage helped to explain racial wealth disparities in the United States, black and Hispanic households still experienced continuing wealth disparities that increased throughout wealth distribution. After accounting for key covariates, nonHispanic black households held $\$ 2,000$ less than non-Hispanic white households in net worth at the 10th percentile, $\$ 61,000$ less at the median, and $\$ 194,000$ less at the 90th percentile. Hispanic households, however, held $\$ 2,800$ more in net worth at the 10th percentile and 45,000 less at the median, with few significant differences at the 90th percentile.

In addition to investigating differences in racial wealth inequality across the wealth distribution, I incorporated a series of decomposition models to examine the relative strength of multiple elements for wealth inequality in my analyses. I found that labor and credit market situations largely accounted for racial disparities in the wealth gaps, but they mattered in different ways for households at opposite ends of the wealth distribution. Assets and debt variables explained more of the wealth gap among low-wealth households, and income and education variables explained more of the gap among high-wealth households. Additionally, within specific assets and debt, homeownership constituted a larger percentage of the racial wealth gap among low-wealth households, and stock ownership held more explanatory power among high-wealth households. Differences in inheritance were also more important for explaining racial wealth gaps at the high end of the distribution, as family inheritance is more accessible among members of this group. Finally, saving regularly, being willing to take financial risks, and seeing credit as acceptablefinancial behaviors that many see as central to building wealth-presented limited associations with the racial wealth gap. 
Despite its contributions, my article, like most analyses, includes certain data and methodological limitations. The first major limitation comes from the measurement of race and ethnicity in the SCF data. The public SCF data contained only four racial identifications of white, black, Hispanic, or "other." Thus, I was only able to ascertain differences among a few racial groups. However, keeping the "other" category within my samples and models also showed that it was rarely a significant predictor of net worth (Appendix Table A of the online supplement). This potentially indicates few differences between these groups and non-Hispanic white households, but the results are also likely affected by sample size.

Using wealth data as an outcome variable also creates some limitations because wealth estimates tend to be inconsistent because of the complexity of wealth, a lack of standardization across surveys, and the difficulty many respondents have in estimating their wealth (Spilerman 2000). To address these issues, the SCF employs strategic sampling to incorporate high-wealth and high-income households and uses imputation to account for missing data. The survey also computes total net worth from detailed debt and asset variables, which improves the reliability of estimates.

Overall, this study highlights the multiple dimensions and predictors of wealth inequality, while expanding knowledge of racial wealth disparities and offering contributions to different areas of research. Empirically and theoretically, this study presents a better picture of racial inequality in net worth with its focus on the entire wealth distribution. My findings show that inequality is not the same across high- and low-wealth households, and predictors of wealth inequality vary across groups. Methodologically, my analysis expands on typical OLS models by using unconditional quantile regression models to examine net worth at different points in the distribution, while incorporating a large set of covariates and potential explanations for racial disparities in net worth with decomposition models. As a result, this research presents a more comprehensive picture of racial wealth inequality in the United States.

\section{Notes}

1 I used code developed by Anthony Damico (https://github.com/ajdamico/asdfree/) to input these data into $\mathrm{R}$ and then pooled the samples myself. Missing data were limited because of the survey's use of imputation.

2 The SCF only provides data for the respondent's race and ethnicity. However, the survey also notes when the race of the spouse differs from that of the respondent. This only occurred in approximately 5 percent of cases.

3 Partners include married or cohabitating couples and spouses.

4 In addition to being an indicator of financial behavior, this variable also likely accounts for certain economic shocks that might affect a household's income and spending balance.

5 For STATA functions for RIF and decomposition procedures, please see Fortin's website: http:/ / faculty.arts.ubc.ca/nfortin/datahead.html.

6 To further expand on this figure, Appendix Table A in the online supplement presents regression results from models that estimated net worth across race and ethnic groups at the 10th, 25th, 50th, 75th, and 90th percentiles of the wealth distribution. 
7 Tables 2 and 3 combine predictor variables into the four sets of explanations for wealth inequality. Appendix Tables B and C in the online supplement include results from detailed decompositions.

\section{References}

Addo, Fenaba R. and Daniel T. Lichter. 2013. “Marriage, Marital History, and Black-White Wealth Differentials Among Older Women." Journal of Marriage and Family 75:342-362. http://dx.doi.org/10.1111/jomf.12007

Avery, Robert B., and Michael S. Rendall. 2002. "Lifetime Inheritances of Three Generations of Whites and Blacks." American Journal of Sociology 107(5):1300-1346. http://dx. doi. org/10.1086/344840

Blinder, Alan S. 1973. “Wage Discrimination: Reduced Form and Structural Estimates." The Journal of Human Resources 8:436-455. http: //dx. doi.org/10. 2307/144855

Board of Governors of the Federal Reserve System. 2014. "Codebook for the 2013 Survey of Consumer Finances." Research Resources: Survey of Consumer Finances. Available online: http:/ / www.federalreserve.gov / econresdata/scf/files/codebk2013.txt.

Bonilla-Silva , Eduardo. 2013. Racism without Racists: Color-Blind Racism and the Persistence of Racial Inequality in America (4th Edition). Lanham, MD: Roman \& Littlefield.

Bricker, Jesse, Lisa J. Dettling, Alice Henriques, Joanne W. Hsu, Kevin B. Moore, John Sabelhaus, Jeffrey Thompson, and Richard A. Windle. 2014. "Changes in U.S. Family Finances from 2010 to 2013: Evidence from the Survey of Consumer Finances." Federal Reserve Bulletin 100(4):1-41.

Campbell, Lori Ann, and Robert L. Kaufman. 2006. "Racial Differences in Household Wealth: Beyond Black and White." Research in Social Stratification and Mobility 24:131-152. http://dx.doi.org/10.1016/j.rssm.2005.06.001

Caskey, John P. 1996. Fringe Banking, Cash-Checking Outlets, Pawnshops, and the Poor. New York, NY: Russell Sage Foundation.

Chiteji, N.S. and Darrick Hamilton. 2002. "Family Connections and the Black-White Wealth Gap Among Middle-Class Families." The Review of Black Political Economy 30(1):9-28. http://dx.doi.org/10.1007/BF02808169

Cohen, Philip N., and Lynne M. Casper. 2002. "In Whose Home? Multigenerational Families in the United States, 1998-2000." Sociological Perspectives 45(1):1-20. http: //dx.doi.org/10.1525/sop.2002.45.1.1

Conley, Dalton. 2001. "Decomposing the Black-white Wealth Gap: The Role of Parental Resources, Inheritance, and Investment Dynamics." Sociological Inquiry 71:39-66. http: //dx.doi.org/10.1111/j.1475-682X.2001.tb00927.x

Conley, Dalton. 1999. Being Black, Living in the Red: Race, Wealth, and Social Policy in America. Berkeley, CA: University of California Press.

DiPrete, Thomas A., and Gregory M. Eirich. 2006. "Cumulative Advantage as a Mechanism for Inequality: A Review of Theoretical Developments." Annual Review of Sociology 32:271-97. http://dx.doi.org/10.1146/annurev.soc.32.061604.123127

Fernandes, Daniel, John G. Lynch Jr., and Richard G. Netemeyer. 2014. "Financial Literacy, Financial Education, and Downstream Financial Behaviors." Management Science 60(8):1861-1883. http://dx.doi.org/10.1287/mnsc. 2013.1849

Firpo, Sergio, Nicole M. Fortin, and Thomas Lemieux. 2009. “Unconditional Quantile Regressions." Econometrica 77(3):953-973. http://dx.doi.org/10.3982/ECTA6822 
Flippen, Chenoa A. 2004. "Unequal Returns to Housing Investments? A Study of Real Housing Appreciation among Black, White, and Hispanic Households." Social Forces 82:1523-51. http://dx.doi.org/10.1353/sof . 2004.0069

Gittleman, Maury, and Edward N. Wolff. 2004. "Racial Differences in Patterns of Wealth Accumulation." Journal of Human Resources 39(1):193-227. http://dx . doi .org/10 . 2307/ 3559010

Heflin, Colleen M., and Mary Pattillo. 2002. "Kin Effects on Black-White Account and Home Ownership." Sociological Inquiry 72(2):220-239. http://dx.doi.org/10.1111/ 1475-682X.00014

Keister, Lisa A. 2004. "Race, Family Structure, and Wealth: The Effect of Childhood Family on Adult Asset Ownership." Sociological Perspectives 47(2):161-187. http: //dx. doi .org/ 10.1525/sop. 2004.47.2.161

Keister, Lisa A. 2003. "Sharing the Wealth: The Effect of Siblings on Adults' Wealth Ownership." Demography 40:521-542.

Keister, Lisa A. 2000a. Wealth in America: Trends in Wealth Inequality. New York: Cambridge University Press. http://dx.doi.org/10.1017/CB09780511625503

Keister, Lisa A. 2000b. "Race and Wealth Inequality: The Impact of Racial Differences in Asset Ownership on the Distribution of Household Wealth." Social Science Research 29:477-502. http://dx.doi.org/10.1006/ssre.2000.0677

Kennickell, Arthur B. and R. Louise Woodburn. 1992. "Estimation of Household Net Worth Using Model-Based and Design-Based Weights: Evidence from the 1989 Survey of Consumer Finances." Working paper, Board of Governors of the Federal Reserve Board. Available online: http://www.federalreserve.gov/pubs/oss/oss2/method.html.

Killewald, Alexandra. 2013. "Return to Being Black, Living in the Red: A Race Gap in Wealth That Goes Beyond Social Origins." Demography 50(4):1177-1195. http://dx.doi .org/10 . 1007/s13524-012-0190-0

Krivo, Lauren J., and Robert L. Kaufman. 2004. "Housing and Wealth Inequality: RacialEthnic Differences in Home Equity in the United States." Demography 41(3):585-605. http://dx.doi.org/10.1353/dem.2004.0023

Kuebler, Meghan, and Jacob S. Rugh. 2013. “New Evidence on Racial and Ethnic Disparities in Homeownership in the United States from 2001 to 2010." Social Science Research 42:1357-1374. http://dx.doi.org/10.1016/j.ssresearch.2013.06.004

Loibl, Cazilia, David S. Kraybill, and Sara Wackler DeMay. 2011. "Accounting for the Role of Habit in Regular Saving." Journal of Economic Psychology 32:581-592. http: //dx.doi.org/10.1016/j.joep.2011.04.004

Lusardi, Annamaria, and Olivia S. Mitchell. 2007. "Financial Literacy and Retirement Preparedness: Evidence and Implications for Financial Education." Business Economics 42:35-44. http://dx.doi.org/10.2145/20070104

Massey, Douglas S. and Nancy Denton. 1993. American Apartheid: Segregation and the Making of the Underclass. Cambridge, MA: Harvard University Press.

McCloud, Laura and Rachel E. Dwyer. 2011. “The Fragile American: Hardship and Financial Troubles in the 21st Century." The Sociological Quarterly 52:13-35. http://dx.doi.org/ $10.1111 / j .1533-8525.2010 .01197 . x$

McKernan, Signe-Mary, Caroline Ratcliffe, Margaret Simms, and Sis Zhang. 2014. “Do Racial Disparities in Private Transfers Help Explain the Racial Wealth Gap? New Evidence from Longitudinal Data." Demography 51:949-974. http://dx.doi .org/10.1007/ s13524-014-0296-7 
Oliver, Melvin, and Thomas Shapiro. 2006. Black Wealth/White Wealth: A New Perspective of Racial Inequality, 10th Anniversary Edition. Routledge.

Oaxaca, Ronald 1973. "Male-Female Wage Differentials in Urban Labor Markets." International Economic Review 14:693-709. http://dx.doi.org/10.2307/2525981

Pager, Devah, and Hana Shepherd. 2008. "The Sociology of Discrimination: Racial Discrimination in Employment, Housing, Credit, and Consumer Markets." Annual Review of Sociology 34:181-209. http://dx. doi .org/10.1146/annurev . soc . 33.040406. 131740

Pfeffer, Fabian T., Sheldon Danziger, and Robert F. Schoeni. 2013. "Wealth Disparities before and after the Great Recession." The ANNALS of the American Academy of Political and Social Science 650(1):98-123. http://dx. doi .org/10.1177/0002716213497452

Reskin, Barbara. 2012. “The Race Discrimination System.” Annual Review of Sociology 38:17-35. http://dx.doi.org/10.1146/annurev-soc-071811-145508

Rubin, Donald B., and Nathaniel Schenker. 1986. “Multiple Imputation for Interval Estimation from Simple Random Samples with Ignorable Nonresponse." Journal of the American Statistical Association 81(394):366-374. http://dx. doi .org/10.1080/01621459. 1986.10478280

Rubin, Donald B. 1996. "Multiple Imputation After 18+ Years." Journal of the American Statistical Association 91(434):473-489. http://dx. doi .org/10.1080/01621459.1996.10476908

Scholz, John Karl, and Ananth Seshadri. 2009. "The Asset and Liabilities of Low-Income Families." Pp. 25-65 in Insufficient Funds: Savings, Assets, Credit, and Banking Among Low-Income Households, edited by R.M. Blank and M.S. Barr. Russell Sage Foundation.

Shapiro, Thomas M. 2004. The Hidden Cost of Being African American: How Wealth Perpetuates Inequality. New York, NY: Oxford University Press.

Spilerman, Seymour. 2000. "Wealth and Stratification Processes." Annual Review of Sociology 26:497-524. http://dx.doi.org/10.1146/annurev.soc.26.1.497

Vespa, Jonathan, and Matthew A. Painter II. 2011. "Cohabitation History, Marriage, and Wealth Accumulation." Demography 48:983-1004. http://dx.doi.org/10.1007/ s13524-011-0043-2

Van Rooij, Maarten, Annamaria Lusardi, and Rob Alessie. 2011. "Financial Literacy and Stock Market Participation." Journal of Financial Economics 101:449-472. http://dx. doi . org/10.1016/j.jfineco.2011.03.006

Wolff, Edward N. 2014. "Household Wealth Trends in the United States, 1983-2010." Oxford Review of Economic Policy 30(1):21-43. http://dx . doi .org/10.1093/oxrep/gru001

Acknowledgements: This research was partially supported by a Social Sciences and Humanities Research Council (SSHRC) Insight Development Grant (\#430-2014-00092).

Michelle Maroto: Department of Sociology, University of Alberta.

E-mail: maroto@ualberta.ca. 